Proc. Indian Acad. Sci. (Chem. Sci.), Vol. 98, No. 3, March 1987, pp.

(c) Printed in India

\title{
Preconcentration of iodide from saline water samples and determina- tion by the catalytic method
}

\author{
K R KRISHNAMOORTHY and R K IYER* \\ Analytical Chemistry Division, Bhabha Atomic Research Centre, Bombay 400 085, India \\ MS received 8 July 1986

\begin{abstract}
A method is described for the determination of nanogram levels of iodide in saline water samples. The interfering chloride, present in milligram levels, is eluted out of a column of a strong anion exchanger, retaining the iodide quantitatively. The iodide is then recovered from the column with $2 \mathbf{M}$ ammonium nitrate solution. The determination is carried out by the catalytic method based on the reduction of $\mathrm{Ce}$ (IV) by $\mathrm{As}$ (III) in presence of jodide. The arresting method was found to be more sensitive. The method can be easily adapted in a field laboratory, with accuracy comparable with neutron activation analysis.
\end{abstract}

Keywords. Iodide; saline waters; preseparation; catalytic method.

\section{Introduction}

Preconcentration of iodide from drinking water and common salt samples followed by its determination by neutron activation analysis was reported by us earlier (Krishnamoorthy and Iyer 1983). The short half-life of I-128 (25 min) necessitates that the laboratory should be situated close to the nuclear reactor. Hence this method cannot be recommended for a field laboratory. The method proposed by Sandell and Kolthoff (1937), based on the catalytic reduction of Ce(IV) by As(III) in presence of iodide, was examined for this purpose. Rodriguez and Purdue (1969) have carried out a detailed study of the factors such as the concentrations of these two reagents, their ratio, temperature and the rate of reaction. Dubravic (1955) arrested the reaction after a fixed time interval by adding $\mathrm{Fe}(\mathrm{II})$ solution which reduces the remaining $\mathrm{Ce}(\mathrm{IV})$ to $\mathrm{Ce}$ (III) producing an equivalent amount of $\mathrm{Fe}(\mathrm{III})$. The absorbance of $\mathrm{Fe}$ (III)-CNS complex is then correlated with the iodide concentration in the system.

The presence of significant amounts of chloride in natural waters of varying salinity imposed a serious limitation on the application of this method for the determination of iodide (Dubravic 1955; Navada et al 1983). This paper describes an anion exchange separation step for eliminating this interference. Further, conditions have been standardized so that the method can be readily adapted in a field laboratory. 


\section{Experimental}

\subsection{Reagents}

Standard iodide solution: $\mathbf{0 . 3 6 1 5} \mathrm{g}$ of AnalaR grade KI was dissolved in deionised water and made up to $200 \mathrm{ml}$ to get a stock solution of $1.382 \mathrm{mg} \mathrm{I} \mathrm{per} \mathrm{ml}$. This solution is suitably diluted to get the working solution of $100 \mathrm{ng} I$ per ml.

As(III) solution, $0.2 \mathrm{M}: 9.98 \mathrm{~g}$ of arsenious oxide was dissolved in dil $\mathrm{NaOH}$, acidified with $\mathrm{H}_{2} \mathrm{SO}_{4}$ and made up to $500 \mathrm{ml}$.

$\mathrm{Ce}(\mathrm{IV})$ solution, $0.01 \mathrm{M}: 4.043 \mathrm{~g}$ ceric ammonium sulphate, tetrahydrate, was dissolved in water containing $90 \mathrm{ml}$ of $1: 1 \mathrm{H}_{2} \mathrm{SO}_{4}$ and made up to 11 .

Ferrous ammonium sulphate solution, $1.5 \% \mathrm{w} / \mathrm{w}$.

Ammonium thiocyanate solution, $4 \% \mathrm{w} / \mathrm{w}$.

Sulphuric acid, $1: 1$.

Ammonium nitrate solution, $0 \cdot 2 \mathrm{M}$ and $2 \mathrm{M}$.

Tulsion A-27 (Gel) anion exchanger, $-50+100$ mesh, in $\mathrm{NO}_{3}$ form.

All dilutions were carried out with deionised water.

A Shimadzu UV-210A double beam spectrophotometer was used for measuring the absorbance of $\mathrm{Ce}(\mathrm{IV})$ at regular intervals and a Beckman model DU spectrophotometer for measuring the absorbance of the $\mathrm{Fe}$ (III)-CNS complex.

In order to demonstrate the validity of the experimental conditions, it was necessary to establish the proportionality of the rate constant with the decrease of the concentration of $\mathrm{Ce}$ (IV) which follows the first order (Rodriguez and Purdue 1969) and the concentration of iodide which remains unchanged during the reaction (Truesdale and Smith 1975). Expressing mathematically,

$$
\begin{aligned}
-\mathrm{d}[\mathrm{Ce}(\mathrm{IV})] / \mathrm{d} t & =\mathrm{k} \cdot[\mathrm{Ce}(\mathrm{IV})] \\
& =\mathrm{k}^{\prime} \cdot[\mathrm{Ce}(\mathrm{IV})] \cdot[\mathrm{I}],
\end{aligned}
$$

where $k$ is the first-order rate constant and is proportional to the concentration of iodide, i.e., $k=k^{\prime}[1]$.

To a series of $10 \mathrm{ml}$ volumetric flasks, containing $0.5 \mathrm{ml}$ of $1: 1 \mathrm{H}_{2} \mathrm{SO}_{4}$ and $0.5 \mathrm{ml}$ of As(III) solution, 0 to $80 \mathrm{ng}$ of iodide were added and the volume kept at $8 \mathrm{ml}$ by adding the requisite amount of deionised water. The flasks were kept in a constant temperature bath (a fish pond with an arrangement to keep the flasks in a stable position) for about 15 minutes. Then exactly $0.5 \mathrm{ml}$ of $\mathrm{Ce}$ (IV) solution was added to the first flask, simultaneously a stop-watch was started. The flask was made up and the absorbance measured at $360 \mathrm{~nm}$ using $1 \mathrm{~cm}$ cells, at regular intervals of 2 to 3 minutes. The experiment was repeated for the other flasks. From the plot of $\log$ (absorbance) vs. the duration of the reaction, the half-time, $T$, for each concentration of iodide was found out. The rate constant $k$, given by $0.693 / T$, is then computed and plotted against iodide concentration. The curve, figure 1 , is linear and passes through the origin, in agreement with the equations proposed by Rodriguez and Purdue (1969) and Truesdale and Smith (1975).

This method involves the measurement of $\mathrm{Ce}$ (IV) concentration over a period of time and obtaining the rate constant graphically. It would be simpler, especially for routine analysis, to make a measurement of $\mathrm{Ce}(\mathrm{IV})$ after a fixed time-interval and 


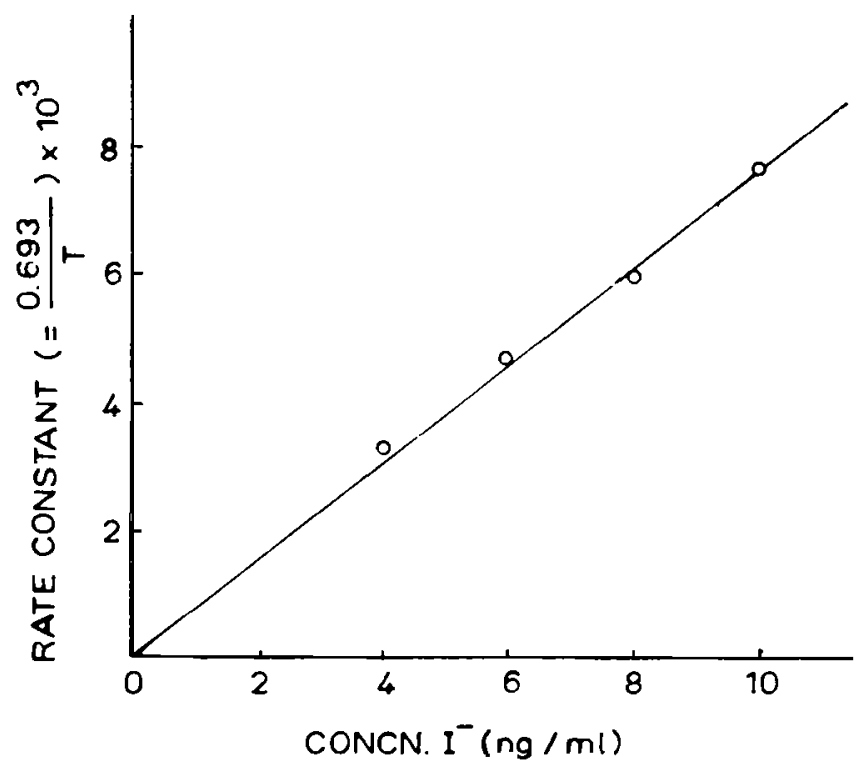

Figure 1. Relation between rate-constant and iodide concentration.

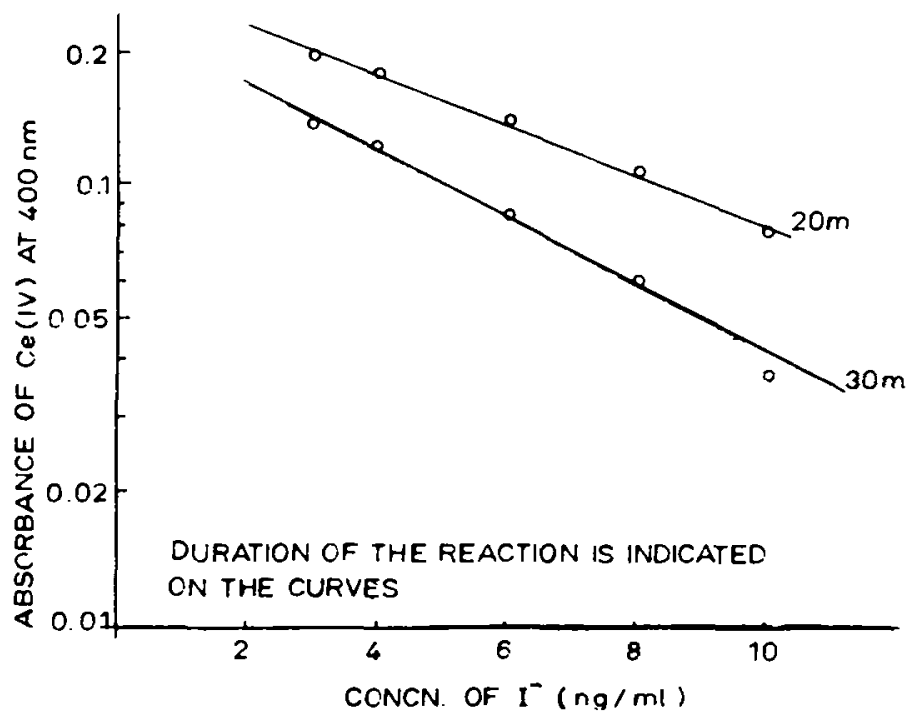

Figure 2. Variation of absorbance of $\mathrm{Ce}(\mathrm{IV})$ with iodide concentration.

correlate this with the iodide concentration. This is shown for two intervals of 20 and 30 minutes in figure 2.

A further improvement in this method has been suggested by Dubravic (1955). This is to arrest the reaction after a chosen time interval by addition of excess of $\mathrm{Fe}$ (II) solution. This converts the remaining $\mathrm{Ce}$ (IV) in the system to an equivalent amount of $\mathrm{Fe}$ (III) which can be conveniently estimated by the absorbance of the $\mathrm{Fe}$ (III)-thiocyanate complex at $460 \mathrm{~nm}$. We found that this method, in addition to being convenient, is also more sensitive. The time interval is chosen such that the 


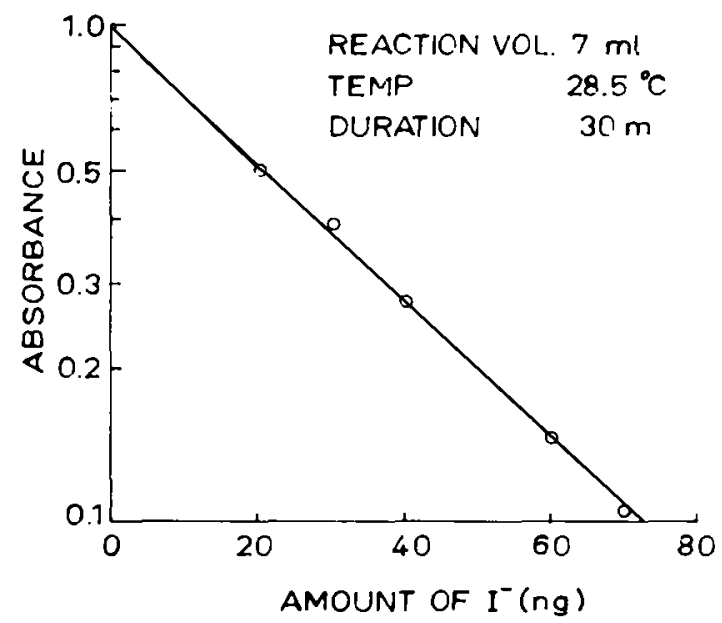

Figure 3. Calibration curve for iodide using the arresting method.

yellow colour of $\mathrm{Ce}(\mathrm{IV})$ just fades. This will be smaller when the iodide concentration is higher and vice versa. The feasibility of using this method in the present case was studied by repeating the experiment, keeping the reaction volume at $7 \mathrm{ml}$. To a series of flasks containing the reagents as before, $0.5 \mathrm{ml}$ of $\mathrm{Ce}$ (IV) solution was added at intervals of $0.5 \mathrm{~min}$. At the end of 30 minutes, the reaction was arrested by adding $0.5 \mathrm{ml}$ of $\mathrm{Fe}$ (II) solution in the same order at intervals of 0.5 minute. The colour was then developed by the addition of $0.5 \mathrm{ml}$ of thiocyanate solution and the absorbance of the complex measured using $1 \mathrm{~cm}$ cells, at $460 \mathrm{~nm}$, after 15 minutes. In this manner, a number of samples could be handled at the same time and analyses carried out conveniently.

Figure 3 gives the calibration curve obtained.

\section{Preseparation}

The presence of chloride in the saline water samples poses a major interference in the analysis by the catalytic method. Thus, the elimination of chloride prior to the determination is required. In our earlier paper, we reported the separation of nanogram amounts of iodide from $1 \mathrm{~g}$ of sodium chloride on a column containing $300 \mathrm{mg}$ of Deacidite FF anion exchanger in the $\mathrm{NO}_{3}$ form. In this step, the chloride content was reduced from $600 \mathrm{mg}$ to less than $0.3 \mathrm{mg}$ in the resin phase, while iodide was retained. The same procedure was followed in the present study. Iodide was recovered subsequently by elution from the column.

Preliminary experiments on $300 \mathrm{mg}$ of Deacidite FF resin indicated that $2 \mathrm{M}$ ammonium nitrate solution eluted nearly $90 \%$ of the iodide within a volume of $10 \mathrm{ml}$, the remaining having been lost in the separation step. Experiments were carried out using $1 \mathrm{~g}$ of the indigenously available Tulsion $\mathrm{A}-27(\mathrm{Gel})$ anion exchanger in the $\mathrm{NO}_{3}$-form. The procedure consisted of loading the saline water sample $(1 \mathrm{ml})$, removal of chloride and bromide with $10 \mathrm{ml}$ of $0.2 \mathrm{M}$ ammonium nitrate, followed by èlution of iodide with $2 \mathrm{M}$ ammonium nitrate $(15 \mathrm{ml})$. The 
Table 1. Elution of iodide from the column.

\begin{tabular}{|c|c|c|c|c|c|c|}
\hline $\begin{array}{l}\text { Weight of resin } \\
\text { Loading volume } \\
\text { Volume per fract } \\
\text { Elution of } \mathrm{Cl}^{-} \text {a } \\
\text { Elution of iodide }\end{array}$ & $\begin{array}{l}\text { tion of } \\
\text { and } \mathrm{Br}\end{array}$ & eluate & $\begin{array}{l}: 1 \\
: 5 \\
: 5 \\
: 5 \\
: 5\end{array}$ & $\begin{array}{l}\text { (N) } \\
\mathrm{nl} \\
\mathrm{nl} \\
\mathrm{nl} \\
\mathrm{nl}\end{array}$ & $\begin{array}{l}\text { form } \\
\text { M NH } \\
\text { tions o }\end{array}$ & $\begin{array}{l}{ }_{4} \mathrm{NO}_{3} \\
\text { of } 2 \mathrm{NH}_{4} \mathrm{NO}_{3}\end{array}$ \\
\hline & Iodide & eluted & in eac & fract & $n(\%)$ & \\
\hline (ng) & 1 & 2 & 3 & 4 & 5 & $(\%)$ \\
\hline 200 & 7.6 & $71 \cdot 5$ & $18 \cdot 1$ & 2.9 & 0.7 & $100 \cdot 8$ \\
\hline 500 & $7 \cdot 7$ & $71 \cdot 2$ & $16 \cdot 2$ & $3 \cdot 8$ & 0.9 & 99.8 \\
\hline 1000 & $2 \cdot 6$ & 83.9 & $9 \cdot 8$ & $1 \cdot 1$ & 0.4 & $97 \cdot 8$ \\
\hline
\end{tabular}

Table 2. Effect of chloride ion.

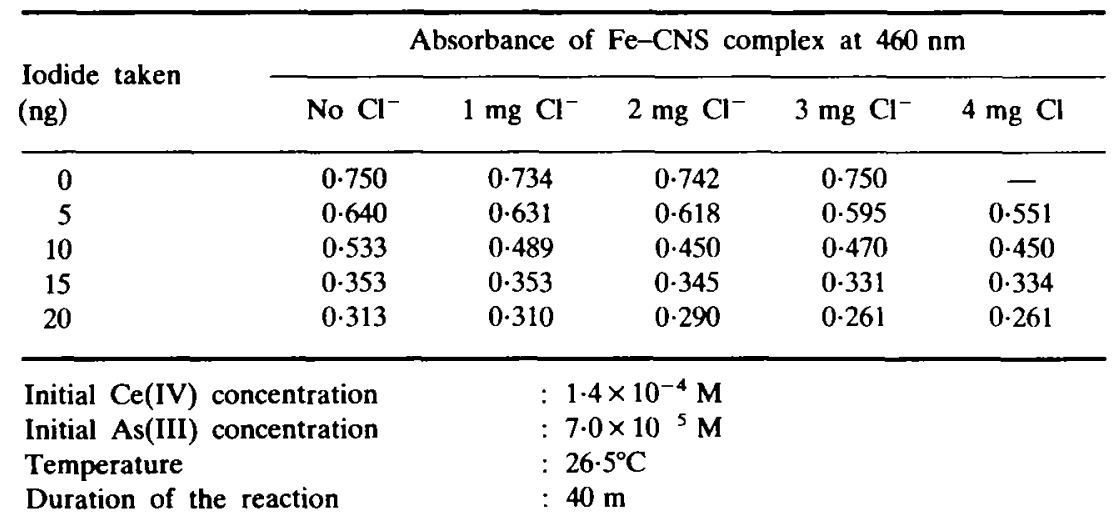

Table 3. Effect of nitrate ion.

\begin{tabular}{lcc}
\hline & \multicolumn{2}{c}{ Absorbance of $\mathrm{Fe}-\mathrm{CNS}$ complex } \\
\cline { 2 - 3 } $\begin{array}{l}\text { Iodide taken } \\
\text { ng) }\end{array}$ & $\mathrm{No} \mathrm{NH}_{4} \mathrm{NO}_{3}$ & $0.5 \mathrm{M} \mathrm{NH}_{4} \mathrm{NO}_{3}$ \\
\hline 10 & 0.418 & 0.382 \\
15 & 0.285 & 0.266 \\
20 & 0.199 & 0.191 \\
25 & 0.149 & 0.153 \\
\hline
\end{tabular}

Temperature: $28 \cdot 5^{\circ} \mathrm{C}$

Duration of reaction: $60 \mathrm{~m}$

recovery by this method for varying amounts of iodide labelled with I-131 tracer is given in table 1 .

Next, the effect of chloride and ammonium nitrate on the determination by the arresting method was studied. Tables 2 and 3 give the results. 


\section{Results and discussion}

The presence of upto $2 \mathrm{mg}$ of chloride in the aliquot used for the determination does not affect the measured value more than $10 \%$. Navada et al (1983) have found no interference from $200 \mathrm{ppm}$ chloride. In view of the decontamination factor of nearly 2000 by this method, even samples containing tens of milligrams of chloride per $\mathrm{ml}$ can be analysed. Similarly, measurements in the presence of $0.5 \mathrm{M}$ ammonium nitrate also indicate no appreciable effect on the measured value. This concentration of $\mathrm{NH}_{4} \mathrm{NO}_{3}$ corresponds to what is expected in the solution used for the measurement, after the elution step.

A few water samples from the coastal areas of Tamil Nadu, containing 0.2 to $30 \mathrm{mg}$ of chloride per $\mathrm{ml}$, were analysed for iodide by the present method. The results are given in table 4 . The first four samples containing $20-50 \mathrm{ppb}$ of iodide were also analysed by neutron activation (Krishnamoorthy and Iyer 1983). The agreement between the results is satisfactory, considering the low levels of concentrations. It further establishes the validity of the separation method, since as much as $28 \mathrm{mg}$ of chloride per $\mathrm{ml}$, present in the sample, does not give a positive interference. In tap water, $0.5 \mathrm{ppb}$ levels of iodide have been determined, and the values compare well with those by the neutron activation technique.

\section{Conclusion}

The method of preseparation and its determination by the catalytic method can be readily adopted in a field laboratory for samples containing 0.5 to $50 \mathrm{ppb}$ of iodide and upto $30 \mathrm{mg}$ of chloride per $\mathrm{ml}$. As reported earlier, the method can be applied for the analysis of common salt also. The chemicals and the anion exchanger are indigenously available and the analysis involves only three steps, namely, (i) anion

Table 4. Analysis of water samples.

\begin{tabular}{cccc}
\hline & \multirow{2}{*}{$\begin{array}{c}\text { Chloride } \\
(\mathrm{mg} / \mathrm{ml})\end{array}$} & \multicolumn{2}{c}{ Conc. of Iodide in ppb } \\
\cline { 4 - 4 } Code nos. & & & \\
& & & \\
Saline waters-I & 0.28 & 39 & 23 \\
171 & 8.15 & 51 & 56 \\
172 & $27 \cdot 8$ & 37 & 71 \\
173 & 1.1 & & 45 \\
175 & & 13 & \\
Saline waters-ll & & 13 & \\
33 & n.a. & 7 & \\
52 & n.a. & 9 & \\
53 & n.a. & & 0.5 \\
75 & n.a. & 0.5 & 0.8 \\
Tap water & & 1.2 & \\
1 & - & & \\
2 & - & & \\
\hline
\end{tabular}

n.a.: not available. 
exchange, separation and elution, (ii) catalytic reaction and (iii) absorbance measurement.

The overall precision of the procedure by the arresting method was found to be $6 \%$ which compares well with the neutron activation analysis.

\section{Acknowledgement}

The authors wish to thank Dr M Sankar Das for his keen interest and encouragement in this work.

\section{References}

Dubravic M 1955 Analyst 80146

Krishnamoorthy K R and Iyer R K 1983 in Trace analysis and technological development (ed.) M Sankar Das (New York: Wiley Eastern) p. 206

Navada S V, Kulkarni U P and Rao S M 1983 in Trace analysis and technological development (ed.) M Sankar Das (New York: Wiley Eastern) p. 257

Rodriguez P A and Purdue H L 1969 Anal. Chem. 411369

Sandell E B and Kolthoff I M 1937 Michrochim. Acta 19

Truesdale V W and Smith P J 1975 Analyst 100111 